\title{
Primary Care in the COVID-19 Pandemic: Essential, and Inspiring
}

\author{
Jennifer E. DeVoe, MD, DPhil and Andrew Bazemore, MD, MPH
}

\section{(J Am Board Fam Med 2021;34:S1-S6.)}

You may encounter many defeats, but you must not be defeated. In fact, it may be necessary to encounter defeats. . so you can know who you are, what you can rise from, how you can still come out of it.

$$
\text { -Maya Angelou }
$$

Spurred by a novel coronavirus pandemic, 2020 will undoubtedly stand out in the annals of history for radically upending the norms of US politics, economy, culture, and race relations and reminding us of the fragility of life as we know it. The US health care system, which has long struggled with fragmentation and poor return on unmatched per-capita spending, further revealed its shortcomings, among them continuing inattention to primary health care, which the world has long declared should be the "central function and main focus [of a] country's health system."1 The disproportionate impact of COVID-19 on disadvantaged communities has shone another bright spotlight on the long-standing health and wealth inequities in our nation and the urgent need to address them., ${ }^{2,3}$

And yet, while facing devastating practice and personal losses ${ }^{4,5}$ from the predictable failure of an archaic fee-for-service-payment system, ${ }^{6,7}$ we've also witnessed inspirational glimpses of the adaptability, innovation, and heroic responses of primary care teams in a time of crisis. ${ }^{8}$ Nearly every person and community in this country has been affected by the COVID-19 pandemic. Family medicine and primary care teams have been here for them in so

From the Department of Family Medicine, Oregon Health \& Science University, Portland, (JED); American Board of Family Medicine and Center for Professionalism \& Value in Health Care, Washington D.C. (AB).

Conflict of interest: None.

Corresponding author: Jennifer E. DeVoe, MD, DPhil, Department of Family Medicine, Oregon Health \& Science University, 3181 Sam Jackson Park Rd, FM, Portland, OR 97239 (E-mail: devoej@ohsu.edu). many different ways. Shifting our modes and manners of care delivery nearly overnight to telehealth ${ }^{9}$ while simultaneously filling gaps in public health, urgent, emergency, inpatient, and intensive care, primary care has risen to the occasion and pushed the limits of what is possible. This special issue highlights many examples of these shifts and also provides a glimpse of the future. For many, primary care adaptations in this crisis also represent longoverdue opportunities for change, ${ }^{10}$ horses now out of the barn whose return is unlikely. ${ }^{11}$ And, while we remain in the middle of this tunnel and unsure of its length, heroic efforts by primary care colleagues and friends have been our lifelines, calming forces, and guiding lights in the darkness.

\section{Adapting and Leading in a Time of Uncertainty}

As the largest platform of health care delivery in the United States, ${ }^{12-14}$ but the recipient of only $5 \%$ to $7 \%$ of all health care investment, ${ }^{15}$ primary care entered the crisis facing greater demand with fewer resources than their more heralded hospital and subspecialty peers. We applaud primary care teams everywhere for their radically adaptative behaviors while preserving and expanding care for the needs of patients and communities over the past year. To comply with physical distancing recommendations, teams have scrambled to comfort patients, build respiratory clinics, ${ }^{16}$ redesign workspaces, develop new protocols, ${ }^{17}$ reschedule visits, and interpret still-evolving regulations about scheduling, documenting, and billing to provide equitable telemedicine services, ${ }^{18}$ often without guarantee of reimbursement. ${ }^{19}$ Teams have faced a tsunami of increasing demands. ${ }^{20}$ These include an increasing volume of calls from worried patients, myriad patient and provider technology challenges ${ }^{21}$ in 
Figure 1. Turning the pandemic crisis into opportunity.

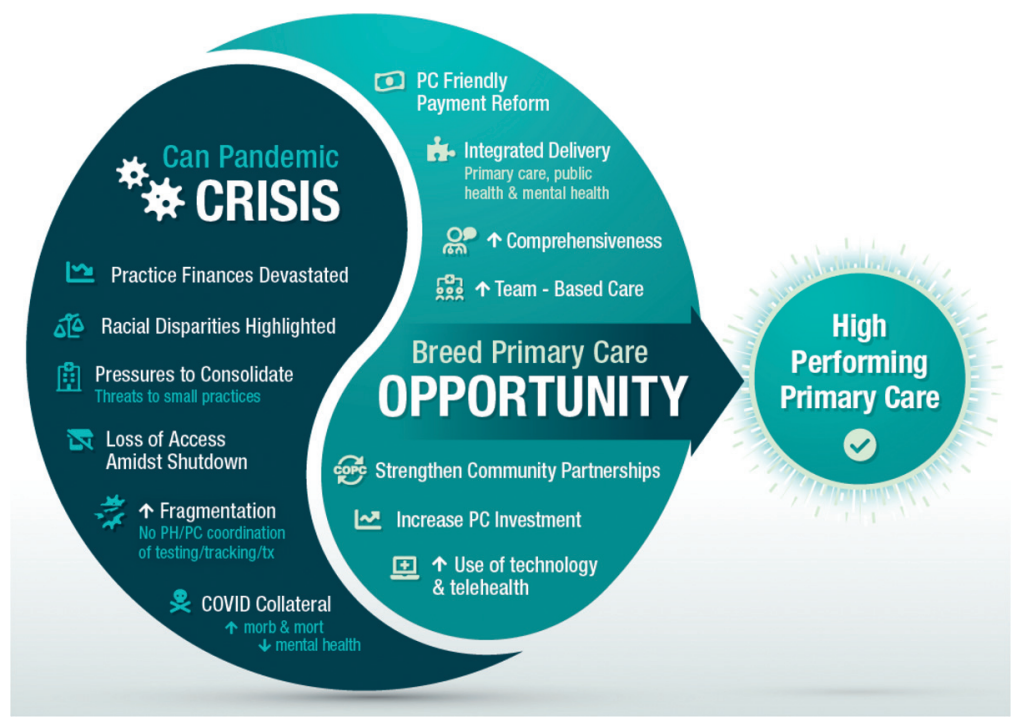

an emergent and unprecedented virtual care environment, nascent testing schemes, and the absence of a national strategy. Yet, our teams have kept up on rapidly changing clinical information, ensured timely access to critical therapies, ${ }^{22,23}$ embraced new team-based models of care, ${ }^{11}$ engaged patients and families in practice improvement, ${ }^{24}$ and rearranged staff schedules when schools closed and waves of COVID-19 rolled through communities. As leaders in "communities of solution" 25 across the country, many primary care clinicians wrote editorials, spoke in public meetings, and worked alongside public health officials and community leaders to provide scientifically sound, trusted, and truthful communications about the novel coronavirus and its deadly risks. Primary care teams partnered with public health teams and practice-based research networks to support discovery ${ }^{26}$ and to augment community education, testing, and contact tracing, accelerating progress toward long-held visions of primary care and public health integration. ${ }^{27}$ The clear message? Primary care is here for them.

\section{Rapid Shifts in Technology and Care Delivery}

Many teams caught up on 20 years of technology in 2 days. Some did more virtual visits in the first few weeks of the pandemic than they had done in an entire career and learned lessons certain to shift the future paradigm of primary care delivery. We showed up on video screens across the country to provide expert guidance and compassionate words to many patients terrified to leave their homes. Our calming, trusted voices were heard through the phone lines for many others who did not have access to video technologies. We rapidly adopted virtual techniques to deliver a whole host of services. $^{28-33}$ We coached patients through video selfexams to evaluate acute abdominal symptoms, to assess an incarcerated hernia, and to diagnose and reduce a nursemaid's elbow. We also rapidly outlined guidelines for determining which visits needed to be in person ${ }^{34}$ and identified conditions that would be exacerbated and disparity gaps that might widen with strict physical distancing requirements ${ }^{35}$ and new inequities in access to testing, vaccination, care management, and digital services. ${ }^{36,37}$ With crazy high levels of uncertainty, primary care teams took it all in stride: questions about COVID19 exposure, physical distancing, stopping or starting medications, "shelter in place" orders, tweets about antimalarials, media recommendations to "call your doctor" for nearly everything, requests for notes to stop working or to return to work after a positive or negative test, or-more likely—no test at all. We did our best to interpret potentially unreliable test results ${ }^{38}$ and to translate national guidance about returning to work after 3 symptom-free days or 7 days since illness started, amid reports 
that infected individuals shed for $>30$ days and the contagiousness of asymptomatic carriers. We persevered when the World Health Organization recommended widespread testing, but frontline realities were scarcity of testing and personal protective equipment (PPE). Amid countless heartbreaking stories of paralyzing fear, jobs lost, housing instability, food insecurity, and uncertainty about the future, primary care teams kept showing up, mobilizing resources, and serving communities across this country. ${ }^{39}$ Again: Primary care is here for them.

\section{Persevering Amid Financial Uncertainty and Limited Resources}

This care has been (and continues to be) rendered while worrying about how to keep staff employed as fee-for-service revenues dropped to almost zero, ${ }^{5,7}$ PPE resources are severely limited, and many sleep separate from family members and stay away from close friends for fear of spreading the virus. Primary care teams built (and rebuilt multiple times!) surge schedules for how we would cover more hospital shifts ${ }^{40}$ and essential services, took crash courses from intensivists to assist with ventilator management, set up drive-through respirator tents, and discussed end-of-life care plans with patients not wanting hospitalization. ${ }^{10}$ When the supply of generalists was too small to meet the demand, some primary care teams stretched capacity by training and redeploying nurses and doctors across their health care system to staff hotlines and mobile testing sites to extend their reach to people in the community without access to primary care and to health care colleagues across their region needing operational and clinical advice. ${ }^{41,42}$ Primary care is here for them.

As serial waves of COVID-19 reverberated through communities across the country, we rapidly developed methods for predicting, understanding, and mitigating risk among our health care colleagues $^{43-45}$ and patient populations ${ }^{46-50}$ and for characterizing novel presentations and new clinical symptoms of COVID-19. ${ }^{51,52} \mathrm{We}$ created new services and ways of delivering care to the mounting numbers of patients recovering from COVID19 in need of home-based rehabilitation care, guidance about returning to work safely, information on how to prevent and how to manage long-term complications, help with family member quarantining, answers to questions about reinfection, and the list goes on. Patients and colleagues who have lost loved ones need grief counseling, and those caring for severely ill loved ones at home need ongoing support. Once more: Primary care is here for them.

\section{Seizing Opportunity from Crisis-Leveraging Pandemic in Pursuit of High-Performing Primary Care}

Despite these seemingly existential struggles, there is opportunity in this crisis for primary care-to emerge stronger, to demonstrate our strengths and what we need to grow stronger, to "break a few things" in a health system that has long neglected primary care's central role (Figure 1). Ironically, as news of a novel coronavirus reached US shores, the National Academies of Medicine seated a committee charged with charting a path to achieve high-performing primary care in the United States, the first on the topic since $1996 .{ }^{53}$ The committee, like the clinics reporting in this special edition, was forced to adapt a long-term vision for primary care to the urgency of a pandemic that is pressure testing our health care system and exposing its crumbling foundation and many fault lines. However, in any crisis, shortcomings and failures also highlight opportunities for strengthening primary care, and emergent best practices such as those in this edition help shine a light on what is needed to enable high-performing primary care teams to thrive and improve the health of the nation.

Not surprisingly, amid intense focus on health system pandemic response and acute care, we've seen alarming rises in all-cause morbidity and mortality well beyond that attributed to COVIDrelated illness. ${ }^{54,55}$ Primary care is uniquely positioned to combat this "COVID collateral" during and after the pandemic, to continue managing chronic diseases and delivering preventive care. ${ }^{56}$ Primary care's critical role in providing mental health care has increased exponentially; similarly, our role in addressing social determinants of health has been a lifeline for socially and economically vulnerable patients. ${ }^{57} \mathrm{We}$ have shown the nation ways to shift the focus to community-based care and away from hospital-based care, as much as possible. ${ }^{58}$ At the same time, primary care physicians have responded to inpatient calls for help, serving alongside hospitalists in supporting hospital efforts to ensure there is more capacity in the emergency 
departments and intensive care units for the patients who do need to be there. Primary care is here for them.

Above all else, this pandemic and special edition have reminded us of what a resilient, inspirational, compassionate bunch of people are drawn to and found in primary care teams, whose good deeds in times of need and crisis are so worthy of celebration! We've also seen in pandemic how perilously close we are to the collapse of the foundational primary care infrastructure that is the bedrock of our health care system and its largest delivery platform. ${ }^{4,13}$ To shore up and strengthen its essential roles and functions postpandemic will require flexible funding structures that move beyond fee-for-service reimbursement, investment in technology and data capabilities that enable meaningful engagement with patients, and data-driven population health work. It also demands training support to grow a skilled and adaptable workforce able to serve patient and community needs, measures that matter and are meaningful to health, and an enhanced research infrastructure to continuously generate new knowledge that can shed light on an evidence-based path forward at an accelerated pace. In short, absent fundamental health system and payment reform change, primary care is here-until it is gone.

We owe a huge debt of gratitude to our primary care colleagues and patients at Oregon Health \& Science University, CUFairfax Family Practice, and the Diplomates of the American Board of Family Medicine whose stories we draw from, and to all our other primary care unsung heroes around the world.

To see this article online, please go to: http://jabfm.org/content/ 34/Supplement/S1.full.

\section{References}

1. World Health Organization. Declaration of AlmaAta International Conference on Primary Health Care, Alma-Ata, USSR, 6-12 September 1978. Available from: https://www.who.int/docs/defaultsource/documents/almaata-declaration-en.pdf?sfvrsn= 7b3c2167_2.

2. Adashi EY, Gruppuso PA. The Centers for Medicare and Medicaid Services (CMS) COVID-19 brief: unsettling racial and ethnic health disparities. J Am Board Fam Med 2021;34(Suppl):S13-S15.

3. Khanna N, Klyushnenkova EN, Kaysin A. Association of COVID-19 with race and socio-economic factors in family medicine. J Am Board Fam Med 2021;34(Suppl):S40-S47.
4. Basu S, Phillips RS, Phillips R, Peterson LE, Landon BE. Primary care practices finances in the United States amid the COVID-19 pandemic. Health Aff (Millwood) 2020;39:1605-1614.

5. Gausvik C, Jabbarpour Y. COVID-19 Timeline: Centers for Medicare and Medicaid Services (CMS) changes and primary care support were not enough to prevent practice losses. J Am Board Fam Med 2021;34(Suppl):S7-S9.

6. DeVoe JE. The incompatibility of patient-centered care with fee-for-service payment. JAMA Intern Med 2020;180:1572.

7. Levey NN. Widening coronavirus crisis threatens to shutter doctors' offices nationwide. Los Angeles Times, March 24, 2020. Available from: https://www. latimes.com/politics/story/2020-03-24/coronavirusoutbreak-primary-care-doctors. Accessed March 24, 2020.

8. Hanna K. Turning life's lemons into sweet lemonade: a positive reflection on the impact of COVID-19. J Am Board Fam Med 2021;34(Suppl):S250-S251.

9. Knierim K, Palmer C, Kramer ES, et al. Lessons learned during COVID-19 that can move telehealth in primary care forward. J Am Board Fam Med 2021;34(Suppl):S196-S202.

10. Bender MA, Huang K-N, Raetz J. Advance care planning during the COVID-19 pandemic. J Am Board Fam Med 2021;34(Suppl):S16-S20.

11. Moreau C. The pharmacist as part of the primary care team during the COVID-19 pandemic. J Am Board Fam Med 2021;34(Suppl):S21-S25.

12. US Centers for Disease Control. National Ambulatory Medical Care Survey: 2016 National Summary Tables. 2016. Available from: https://www.cdc.gov/ nchs/data/ahcd/namcs_summary/2016_namcs_web_ tables.pdf.

13. White KL, Williams F, Greenberg BG. The ecology of medical care. N Engl J Med 1961;265:885-892.

14. Green LA, Fryer GE, Yawn BP, Lanier D, Dovey SM. The ecology of medical care revisited. N Engl J Med 2001;344:2021-2025.

15. Martin S, Phillips RL, Jr, Petterson S, Levin Z, Bazemore AW. Primary care spending in the United States, 2002-2016. JAMA Intern Med 2020;180:1019-1020.

16. Westfall JM, Jetty A, Petterson S, Jabbarpour Y. Site of care for COVID-19-like respiratory illness. J Am Board Fam Med 2021;34(Suppl):S26-S28.

17. O'Gurek DT. Designing and evaluating COVID19 protocols for an office-based opioid treatment program in an urban underserved setting. $\mathrm{J}$ Am Board Fam Med 2021;34(Suppl):S136-S140.

18. Westby A, Nissly T, Gieseker R, Timmins K, Justesen K. Achieving equity in telehealth: "centering at the margins" in access, provision, and reimbursement. J Am Board Fam Med 2021;34(Suppl): S29-S33. 
19. Coronavirus: family physicians provide telehealth care at risk of bankruptcy. USA Today. April 12, 2020. Available from: https://www.usatoday. com/story/opinion/2020/04/07/coronavirus-familyphysicians-provide-telehealth-care-risk-bankruptcycolumn/2942535001/.

20. The COVID-19 tsunami: the tide goes out before it comes in. Health Affairs Blog. 2020. Available from: https://www.healthaffairs.org/do/10.1377/ hblog20200415.293535/full/.

21. Jetty A, Jabbarpour Y, Westfall M, Kamerow DB, Petterson S, Westfall J. Capacity of primary care to deliver telehealth in the United States. J Am Board Fam Med 2021;34(Suppl):S48-S54.

22. Patel P, Narayana S, Thill Z, Gold M, Paul A. Family physicians' role in simplifying medication abortion during the COVID-19 pandemic. J Am Board Fam Med 2021;34(Suppl):S33-S36.

23. Robbins JL, Englander H, Gregg J. Buprenorphine microdose induction for the management of prescription opioid dependence. J Am Board Fam Med 2021;34(Suppl):S141-S146.

24. Schlaudecker JD, Goodnow K. The virtual patient and family advisory council in the COVID era. J Am Board Fam Med 2021;34(Suppl):S37-S39.

25. Folsom Group. Communities of solution: the Folsom Report revisited. Ann Fam Med 2012;10:250-60.

26. DeVoe JE, Likumahuwa-Ackman SM, Angier HE, et al. A practice-based research network (PBRN) roadmap for evaluating COVID-19 in community health centers: a report from the OCHIN PBRN. J Am Board Fam Med 2020;33:774-778.

27. Westfall JM, Liaw W, Griswold K, et al. Uniting public health and primary care for healthy communities in the COVID-19 era and beyond. J Am Board Fam Med 2021;34(Suppl):S203-S209.

28. Careyva BA, Greenberg G, Kruklitis R, Shaak K, Stoeckle JJ, Stephens J. Key factors promoting rapid implementation of virtual screening modalities for the COVID-19 pandemic response. J Am Board Fam Med 2021;34(Suppl):S55-S60.

29. Gomez T, Anaya YB, Shih KJ, Tarn DM. A qualitative study of primary care physicians' experiences with telemedicine during COVID-19. J Am Board Fam Med 2021;34(Suppl):S61-S70.

30. Volcy J, Smith W, Mills K, et al. Assessment of patient and provider satisfaction with the change to telehealth from in-person visits at an academic safety net institution during the COVID-19 pandemic. J Am Board Fam Med 2021;34(Suppl):S71S76.

31. Tarn DM, Hintz C, Mendez-Hernandez E, Sawlani SP, Bholat MA. Using virtual visits to care for primary care patients with COVID-19 symptoms. J Am Board Fam Med 2021;34(Suppl):S147S151.
32. Silver SL, Lewis MN, Ledford CJW. A stepwise transition to telemedicine in response to COVID19. J Am Board Fam Med 2021;34(Suppl):S152S161.

33. Edgoose JYC. Exploring the face-to-face: revisiting patient-doctor relationships in a time of expanding telemedicine. J Am Board Fam Med 2021;34 (Suppl):S252-S254.

34. Jabbarpour Y, Jetty A, Westfall M, Westfall J. Not telehealth: which primary care visits need in-person care? J Am Board Fam Med 2021;34(Suppl):S162_ S169.

35. Licciardone JC. Demographic characteristics associated with utilization of noninvasive treatments for chronic low back pain and related clinical outcomes during the COVID-19 pandemic in the United States. J Am Board Fam Med 2021;34(Suppl):S77_ S84.

36. Sieck CJ, Rastetter M, McAlearney AS. Could telehealth improve equity during the COVID-19 pandemic? J Am Board Fam Med 2021;34(Suppl): S225-S228.

37. Taylor NK, Aboelata N, Mahoney $M$, et al. Building bridges between community health centers and academic medical centers in a COVID-19 pandemic. J Am Board Fam Med 2021;34(Suppl):S229_ S232.

38. Piltch-Loeb R, Jeong KY, Lin KW, Kraemer JD, Stoto MA. Interpreting COVID-19 test results in clinical settings: it depends!. J Am Board Fam Med 2021;34(Suppl):S233-S243.

39. Damian AJ, Gonzalez M, Oo M, Anderson D. A national study of community health centers' readiness to address COVID-19. J Am Board Fam Med 2021;34(Suppl):S85-S94.

40. Devitt J, Malam N, Montgomery L. A family medicine residency program's response to an impending COVID-19 surge. J Am Board Fam Med 2021;34 (Suppl):S217-S221.

41. Margolius D, Hennekes M, Yao J, et al. On the front (phone) lines: results of a COVID-19 hotline. J Am Board Fam Med 2021;34(Suppl):S95-S102.

42. Cheng A, Angier H, Huguet N, et al. Launching a statewide COVID-19 primary care hotline and telemedicine service. J Am Board Fam Med 2021;34 (Suppl):S170-S178.

43. Chu E, Lee K-M, Stotts R, et al. Hospital-based health care worker perceptions of personal risk related to COVID-19. J Am Board Fam Med 2021;34(Suppl):S103-S112.

44. Toselli M, Palazzi I, Lambertini $M$, et al. Teachings after COVID-19 outbreak from a survey on family physicians. J Am Board Fam Med 2021;34(Suppl):S222-S224.

45. Gouda D, Mohinder Singh P, Gouda P, Goudra B. An overview of health care worker reported deaths 
during the COVID-19 pandemic. J Am Board Fam Med 2021;34(Suppl):S244-S246.

46. Bentivegna M, Hulme C, Ebell MH. Primary care relevant risk factors for adverse outcomes in patients with COVID-19 infection: a systematic review. J Am Board Fam Med 2021;34(Suppl): S113-S126.

47. Yang M-J, Rooks BJ, Le T-T, et al. Influenza vaccination and hospitalizations among COVID-19 infected adults. J Am Board Fam Med 2021;34(Suppl):S179_ S182.

48. Smith JA, Basabose J, Brockett M, Browne DT, Shamon S, Stephenson M. Family medicine with refugee newcomers during the COVID-19 pandemic. J Am Board Fam Med 2021;34(Suppl):S210S216.

49. Ebell MH, Cai X, Lennon R, et al. Development and validation of the COVID-NoLab and COVIDSimpleLab risk scores for prognosis in 6 US health systems. J Am Board Fam Med 2021;34(Suppl): S127-S135.

50. Huguet N, Schmidt T, Larson A, et al. Prevalence of pre-existing conditions among community health center patients with COVID-19: implications for the Patient Protection and Affordable Care Act. J Am Board Fam Med 2021;34(Suppl):S247-S249.

51. Phamduy TT, Young DM, Ramolia PB. Localized scarlatiniform rash of the ears and antecubital fossa in COVID-19. J Am Board Fam Med 2021;34(Suppl):S183-S185.

52. Kwon E, Whitlow N, Reed A. A review of clinical and laboratory predictors of severe COVID-19 disease. J Am Board Fam Med 2021;34(Suppl): S186-S191.

53. Implementing high-quality primary care. 2020. Available from: https://www.nationalacademies.org/ our-work/implementing-high-quality-primary-care.

54. Kontis V, Bennett JE, Rashid T, et al. Magnitude, demographics and dynamics of the effect of the first wave of the COVID-19 pandemic on all-cause mortality in 21 industrialized countries. Nat Med 2020;26:1919-28.

55. Lange SJ, Ritchey $\mathrm{MD}$, Goodman $\mathrm{AB}$, et al. Potential indirect effects of the COVID-19 pandemic on use of emergency departments for acute life-threatening conditions-United States, JanuaryMay 2020. MMWR Morb Mortal Wkly Rep 2020;69:795-800.

56. Ledford CJW, Roberts C, Whisenant E, et al. Quantifying worsened glycemic control during the COVID-19 pandemic. J Am Board Fam Med 2021;34(Suppl):S192-S195.

57. Drake C, Eisenson H. Assessing and addressing social needs in primary care. N Engl J Med Catalyst, November 6, 2019. Available from: https://catalyst. nejm.org/doi/full/10.1056/CAT.19.0693. Accessed March 30, 2020.

58. Nacoti M, Ciocca A, Giupponi A, et al. At the epicenter of the COVID-19 pandemic and humanitarian crises in Italy: changing perspectives on preparation and mitigation. N Engl J Med Catalyst, March 21, 2020. Available from: https://catalyst. nejm.org/doi/full/10.1056/CAT.20.0080. Accessed March 23, 2020. 